\title{
Highlight report: mitochondrial depolarization by ethanol
}

\author{
Raymond Reif ${ }^{1}$
}

Published online: 5 November 2015

(C) Springer-Verlag Berlin Heidelberg 2015

Recently, a study has been published by the group of John Lemasters, showing that high acute doses of ethanol in mice cause a widespread but reversible depolarization of mitochondria (Zhong et al. 2014). In their study, Zhong and colleagues used a two-photon imaging with vital dyes to visualize mitochondrial potential. This technique allows generating videos of the living organ with a spatial resolution of approximately $200 \mathrm{~nm}$. Living mice received injections of Rhodamine 123, a cationic fluorophore that is taken up by polarized mitochondria and by its green fluorescence indicates mitochondrial activity (Zhong et al. 2014). Loss of green fluorescence signal indicates mitochondrial depolarization. The authors administered $6 \mathrm{~g} / \mathrm{kg}$ ethanol, a very high dose, corresponding to extreme 'binge drinking.' As a consequence, a transient mitochondrial depolarization of almost all hepatocytes was observed. More than $24 \mathrm{~h}$ were required until mitochondria returned to the control situation (Zhong et al. 2014). Mitochondrial depolarization depends on ethanol metabolism, since deficiency of CYP2E1 as well as alcohol dehydrogenase antagonized the effect (Zhong et al. 2014).

The paper of Zhong and colleagues describes a novel and amazing phenomenon. It may seem surprising that depolarization occurs as an all-or-nothing phenomenon. This suggests that ethanol acts by a so far unknown threshold mechanism. It is of interest to learn whether transient mitochondrial depolarization and consequently compromised energy metabolism disturb further hepatocellular

Raymond Reif

reif@ifado.de

1 Leibniz Research Centre for Working Environment and Human Factors, IfADo, Ardeystr. 67, 44139 Dortmund, Germany functions, such as drug metabolism. In the past decade, numerous projects focused on organotypical in vitro systems with human and rodent hepatocytes (Hewitt et al. 2007; Schug et al. 2013; Reif 2014a, b; Reif et al. 2015; Godoy et al. 2013, 2015). In case it is possible to mimic this transient depolarization in vitro, one can use human hepatocytes to determine whether similar mechanisms are active also in human. Recently, mitochondrial dysregulation has been described as a key mechanism of numerous chemicals (Bonifacio et al. 2014; Yang et al. 2014; McGill et al. 2014; Monteiro et al. 2013), oxidative stress-induced adverse effects (Toledo et al. 2014; Sinha et al. 2013) but also in adaptive responses (Nair et al. 2014; Lu et al. 2013). Moreover, mitochondria represent one of the most frequent targets in drug-induced liver injury (Lancaster et al. 2015; Schyschka et al. 2013). In future, it will be interesting to learn how ethanol-induced mitochondrial depolarization influences liver physiology and susceptibility of the hepatocytes to chemicals.

\section{References}

Bonifacio A, Mullen PJ, Mityko IS, Navegantes LC, Bouitbir J, Krähenbühl S (2014) Simvastatin induces mitochondrial dysfunction and increased atrogin-1 expression in $\mathrm{H} 9 \mathrm{c} 2$ cardiomyocytes and mice in vivo. Arch Toxicol. doi:10.1007/ s00204-014-1378-4

Godoy P, Hewitt NJ, Albrecht U, Xu JJ, Yarborough KM, Hengstler JG (2013) Recent advances in 2D and 3D in vitro systems using primary hepatocytes, alternative hepatocyte sources and nonparenchymal liver cells and their use in investigating mechanisms of hepatotoxicity, cell signaling and ADME. Arch Toxicol 87(8):1315-1530

Godoy P, Schmidt-Heck W, Natarajan K, Lucendo-Villarin B, Szkolnicka D, Asplund A, Bjorquist P, Widera A, Stoeber R, Campos G, Hammad S, Sachinidis A, Damm G, Weiss TS, Nussler A, Synnergren J, Edlund K, Küppers-Munther B, Hay D, Hengstler 
JG (2015) Gene networks and transcription factor motifs defining the differentiation of stem cells into hepatocyte-like cells. J Hepatol 63(4):934-942. doi:10.1016/j.jhep.2015.05.013

Hewitt NJ, Lechón MJ, Houston JB, Hallifax D, Brown HS, Maurel P, Kenna JG, Gustavsson L, Lohmann C, Skonberg C, Guillouzo A, Tuschl G, Li AP, LeCluyse E, Groothuis GM, Hengstler JG (2007) Primary hepatocytes: current understanding of the regulation of metabolic enzymes and transporter proteins, and pharmaceutical practice for the use of hepatocytes in metabolism, enzyme induction, transporter, clearance, and hepatotoxicity studies. Drug Metab Rev 39(1):159-234

Lancaster EM, Hiatt JR, Zarrinpar A (2015) Acetaminophen hepatotoxicity: an updated review. Arch Toxicol 89(2):193-199. doi:10.1007/s00204-014-1432-2

Lu Y, Pei Y, Shao Y, Yan S, Ma L, Fang F, Jin M, Liu M, Li J, Li C (2013) Hepatotoxicity induced by zoledronic acid in an aged woman with primary osteoporosis. EXCLI J 12:115-117

McGill MR, Li F, Sharpe MR, Williams CD, Curry SC, Ma X, Jaeschke H (2014) Circulating acylcarnitines as biomarkers of mitochondrial dysfunction after acetaminophen overdose in mice and humans. Arch Toxicol 88(2):391-401. doi:10.1007/ s00204-013-1118-1

Monteiro JP, Pereira CV, Silva AM, Maciel E, Baldeiras I, Peixoto F, Domingues MR, Jurado AS, Oliveira PJ (2013) Rapeseed oilrich diet alters hepatic mitochondrial membrane lipid composition and disrupts bioenergetics. Arch Toxicol 87(12):2151-2163. doi:10.1007/s00204-013-1068-7

Nair AR, Lee WK, Smeets K, Swennen Q, Sanchez A, Thévenod F, Cuypers A (2014) Glutathione and mitochondria determine acute defense responses and adaptive processes in cadmiuminduced oxidative stress and toxicity of the kidney. Arch Toxicol. doi:10.1007/s00204-014-1401-9

Reif R (2014a) Concepts of predictive toxicology. EXCLI J 13:1292-1294

Reif R (2014b) The body-on-a-chip concept: possibilities and limitations. EXCLI J 13:1283-1285
Reif R, Karlsson J, Günther G, Beattie L, Wrangborg D, Hammad S, Begher-Tibbe B, Vartak A, Melega S, Kaye PM, Hengstler JG, Jirstrand M (2015) Bile canalicular dynamics in hepatocyte sandwich cultures. Arch Toxicol 89(10):1861-1870. doi:10.1007/ s00204-015-1575-9

Schug M, Stöber R, Heise T, Mielke H, Gundert-Remy U, Godoy P, Reif R, Blaszkewicz M, Ellinger-Ziegelbauer H, Ahr HJ, Selinski S, Günther G, Marchan R, Blaszkewicz M, Sachinidis A, Nüssler A, Oberemm A, Hengstler JG (2013) Pharmacokinetics explain in vivo/in vitro discrepancies of carcinogen-induced gene expression alterations in rat liver and cultivated hepatocytes. Arch Toxicol 87(2):337-345. doi:10.1007/s00204-012-0999-8

Schyschka L, Sánchez JJ, Wang Z, Burkhardt B, Müller-Vieira U, Zeilinger K, Bachmann A, Nadalin S, Damm G, Nussler AK (2013) Hepatic 3D cultures but not 2D cultures preserve specific transporter activity for acetaminophen-induced hepatotoxicity. Arch Toxicol 87(8):1581-1593. doi:10.1007/s00204-013-1080-y

Sinha K, Das J, Pal PB, Sil PC (2013) Oxidative stress: the mitochondria-dependent and mitochondria-independent pathways of apoptosis. Arch Toxicol 87(7):1157-1180. doi:10.1007/ s00204-013-1034-4

Toledo FD, Pérez LM, Basiglio CL, Ochoa JE, Sanchez Pozzi EJ, Roma MG (2014) The $\mathrm{Ca}^{2+}$-calmodulin- $\mathrm{Ca}^{2+} /$ calmodulindependent protein kinase II signaling pathway is involved in oxidative stress-induced mitochondrial permeability transition and apoptosis in isolated rat hepatocytes. Arch Toxicol 88(9):16951709. doi:10.1007/s00204-014-1219-5

Yang Y, Liu H, Liu F, Dong Z (2014) Mitochondrial dysregulation and protection in cisplatin nephrotoxicity. Arch Toxicol 88(6):12491256. doi:10.1007/s00204-014-1239-1

Zhong Z, Ramshesh VK, Rehman H, Liu Q, Theruvath TP, Krishnasamy Y, Lemasters JJ (2014) Acute ethanol causes hepatic mitochondrial depolarization in mice: role of ethanol metabolism. PLoS ONE 9(3):e91308. doi:10.1371/journal.pone.0091308 